\section{A referência linguística na atenção conjunta}

\section{Linguistic reference in joint attention}

José Moacir Soares da COSTA FILHO (IFPB) jmscostafilho@gmail.com
COSTA FILHO, José Moacir Soares da. A referência linguística na atenção conjunta. Entrepalavras, Fortaleza, v. 7, p. 188-205, ago./dez. 2017.

Resumo: O objetivo deste artigo é discutir a relação entre a atenção conjunta e a referência linguística. Para tanto, analisamos qualitativamente dados coletados com vinte crianças de 2 a 5 anos de idade enquanto elas jogavam um aplicativo para tablets. Nossa análise inicialmente tem como suporte teórico as contribuições de Bruner (1975) eTomasello (2003) acerca da atenção conjunta. Em seguida, trazemos Diessel (2006) e Costa Filho (2011, 2013 e 2016) para discutir a importância da atenção conjunta durante o processo de consolidação da referência linguística para a criança. Após a análise dos dados, encontramos três tipos de atenção conjunta: atual, composicional e virtual, por meio das quais pudemos perceber que a atenção conjunta e o processo de referência linguística são interdependentes, já que é por meio das noções de referência linguística que os sujeitos da interação se engajam nas cenas de atenção conjunta.

Palavras-chave: Atenção conjunta. Referência linguística. Interação virtual. 
Abstract: The aim of this paper is to discuss the relationship between joint attention and linguistic reference. Therefore, we analyzed data collected with twenty children ranging from 2 to 5 years old while they played with an app for tablets. Firstly our analysis has the contributions of Bruner (1975) e Tomasello (2003) about joint attention as theoretical support. Secondly we quote Diessel (2006) and Costa Filho $(2011,2013,2016)$ to discuss the importance of joint attention during the consolidation of linguistic reference by the child. The analysis of the data showed three types of joint attention: present, composed and virtual, through which we could notice that the joint attention and the process of linguistic reference are interdependent, since it is through the notions of linguistic reference that the subjects in interaction engage in joint attention scenes.

Keywords: Joint attention. Linguistic reference. Virtual interaction.

\section{Introdução}

A teoria da atenção conjunta tem seus primeiros registros a partir das pesquisas de Bruner (1975) e está inserida em um panorama teórico em que a interação entre sujeitos é o ponto de partida para a observação de processos que envolvem a cognição.

Bruner (1975; 1983) aborda a atenção conjunta como um das estratégias das quais a criança, que ainda não domina as estruturas linguísticas, faz uso para garantir seu lugar nas trocas interativas que estabelece com os adultos que a cercam desde o seu nascimento.

Partindo desse mesmo posicionamento teórico, Tomasello (2003) contribui com a teoria da atenção conjunta e seus estudos podem ser vistos como um dos mais importantes a respeito do tema. Investigando o processo de atenção e suas contribuições para o desenvolvimento cognitivo, este teórico se debruça sobre dados tanto de bebês humanos quanto de chimpanzés para compreender de que forma o estabelecimento da atenção conjunta pode contribuir para o engajamento em rotinas interativas e, no caso das crianças humanas, de que forma a atenção conjunta se constitui como um formato favorável à aquisição da linguagem.

Embora a atenção conjunta seja uma teoria que perpassa áreas distintas, como Psicologia Cognitiva, Primatologia e Linguística, é sobre esta que refletimos no presente artigo, no qual temos por objetivo discutir o processo de construção da referência linguística dentro da atenção conjunta.

Para que possamos alcançar nosso objetivo, é necessário inicialmente compreender a relação entre a atenção conjunta e a referência linguística, o que faremos a seguir. 
v. 7 (2) 188-205 ago/dez 2017

\section{Atenção conjunta e referência linguística}

O processo que recebe o nome de atenção conjunta pode ser compreendido por meio da definição de Tomasello (2003) que destaca este como um processo em que adulto e criança têm a atenção voltada para um mesmo objeto foco e ainda a atenção mútua que ambos mantêm, por um período razoável de tempo.

As contribuições da atenção conjunta para os estudos sobre aquisição da linguagem podem ser vistas a partir de pesquisas que privilegiam a interação como lócus no qual a criança se insere na língua. Dentre as contribuições mais relevantes, está a aquisição de novas palavras, já que, durante os episódios de atenção conjunta, o adulto pode trazer determinados objetos focos que, ao se tornarem tópicos da interação, são apresentados à criança que está em processo de aquisição vocabular.

Dentre os estudos que discutem a importância da atenção conjunta na aquisição da linguagem, prevalecem aqueles em que as crianças cujos dados são analisados estão numa faixa etária de zero a dois anos de idade, ou seja, crianças que estão no início do processo de aquisição da linguagem. Entretanto, é possível notar, por meio de algumas pesquisas mais recentes sobre o tema, que a atenção conjunta não se dilui com o passar da infância e que, como mostram Diessel (2006) e Costa Filho (2011; 2013; 2016) - apenas para citar dois exemplos -, este processo interativo continua fazendo parte da rotina infantil e auxilia a aquisição de processos cuja complexidade aumenta na medida em que a criança ultrapassa os dois anos de vida.

Uma das justificativas apresentadas por Diessel (2006) e compartilhada por Costa Filho (2011; 2013; 2016) para o estudo da atenção conjunta com crianças maiores que dois anos de idade é o fato de que este processo está associado à consolidação da referência linguística no que se refere à pessoa, ao tempo e ao espaço, algo que, como aponta Cairns (1991), envolve a compreensão de conceitos e relações que são naturalmente mais complexas dentro da aquisição da linguagem infantil. Nesse sentido, trazemos a ideia de que a atenção conjunta engloba e compartilha elementos e funcionamentos semelhantes aos que estão presentes no processo referencial ${ }^{1}$.

\footnotetext{
${ }^{1}$ Este artigo apresenta um recorte de nossa Tese de Doutorado em Linguística, intitulada "Atenção conjunta: o jogo da referência na realidade virtual", defendida em 2016 pelo Programa de Pós-Graduação em Linguística da Universidade Federal da Paraíba (Proling-UFPB).
} 
Corroborando essa ideia, autores como Bruner (1983) relacionam a referência linguística ao processo de atenção conjunta como um ato comunicativo por meio do qual o sujeito indica na interação com outros um dado elemento no espaço. Para este autor, a construção desse ato referencial envolve quatro pressupostos:

(i) o primeiro corresponde à intenção (sic) referencial do sujeito, algo que, na atenção conjunta, é marcado pela intenção comunicativa do participante em destacar o elemento foco;

(ii) o segundo pressuposto associa-se à forma como cada indivíduo se refere a um tópico determinado. Se pensarmos na aplicação desse pressuposto ao processo de atenção conjunta, percebemos que há na atenção conjunta uma negociação entre os parceiros que no processo estão inseridos. Essa negociação tem a ver com os meios pelos quais adulto e criança se referem ao foco da atenção conjunta e ritualizam esse formato;

(iii) o terceiro pressuposto mencionado por Bruner (1983) é a noção de referência como forma de interação social, assim como a atenção conjunta. Por meio deste pressuposto, percebemos que a referência e a atenção conjunta são processos interdependentes, uma vez que, para se iniciar a atenção conjunta, é preciso que haja um objeto referenciado, e, ao mesmo tempo, para que se consolide a referência, é preciso que a cena de atenção conjunta esteja também consolidada. Esse terceiro pressuposto, portanto, permite-nos ver que a atenção conjunta não é necessariamente a porta de entrada da referência linguística, mas sim o lócus no qual os atos referenciais se consolidam, o que indica a imbricação dos dois processos (atenção conjunta e referência linguística);

(iv) por fim, por meio do quarto pressuposto apontado por Bruner (1983), notamos que a relação entre estrutura e objetivo no ato referencial é mantida não somente pela intenção (sic) de se referir a algo, mas também por meios que variam a partir dos dispositivos linguísticos utilizados e que permitem conceber como anáfora o ato de fazer referência ao texto e como dêixis o ato de fazer referência ao contexto².

${ }^{2}$ Bruner (1983, p. 68) apresenta anáfora e dêixis como processos distintos que variam de acordo com o que está sendo referenciado. 
v. 7 (2) 188-205 ago/dez 2017

É do quarto pressuposto que extraímos um entendimento muito relevante para nossa discussão. Tendo em vista que, em nossa pesquisa, não temos por objetivo examinar as relações referenciais por meio das quais os sujeitos na interação retomam termos e/ou expressões verbais empregados no discurso, mas sim as relações que permitem o estabelecimento da atenção conjunta, percebemos que este processo referencial ocorre no contexto. Logo, isso enfatiza que o ato de referenciar por meio do contexto no qual a interação ocorre é sustentando pela atenção conjunta.

A relação entre a dêixis e o contexto da atenção conjunta também pode ser vista por meio das contribuições de Koch (1998) e Marcuschi (1997) ao tema. Ao definir dêixis, Koch (1998) destaca que este é um funcionamento por meio do qual um falante direciona a atenção do ouvinte a um item específico situado no domínio discursivo em que os sujeitos estão situados, ou seja, o espaço dêitico. Sendo assim, já que a atenção conjunta se estrutura com um sujeito direcionando a atenção do outro a um determinado elemento, percebemos que o espaço dêitico a que a autora se refere pode ser ilustrado pelas cenas de atenção conjunta.

Marcuschi (1997) segue um caminho semelhante na discussão da dêixis. Como mostram Silva, Lira e Cavalcanti (2001), o pesquisador separa a dêixis em quatro tipos principais: pessoal, espacial, temporal e discursiva, referindo-se à última como uma estratégia de monitoração cognitiva acerca dos focos de atenção na atividade dialógica. Seria a dêixis discursiva, então, o funcionamento por meio do qual os sujeitos inseridos na cena de atenção conjunta engajam-se e verificam a existência da atenção mútua.

Triadó (1999, p. 683), embora perceba a dêixis dentro de uma perspectiva semelhante a de Marcuschi (1997) e contribua para a compreensão do processo discutido, não traz o quarto tipo. Para a autora, a dêixis ocorre em três categorias. A primeira, dêixis pessoal, indica os lugares no discurso de quem fala, de quem ouve e do tópico sobre que ou quem se fala. A segunda refere-se à indicação do tempo no discurso, sendo nomeada de dêixis temporal. Já a terceira, a dêixis espacial, corresponde às estratégias utilizadas para fazer referência a um elemento (objeto, pessoa, evento) no espaço (visível ou não).

$\mathrm{Na}$ atenção conjunta, percebemos que estão presentes as dêixis de pessoa, espaço e tempo, já que este processo interativo é composto por: 
i) sujeitos que intercalam os papéis discursivos marcados pela dêixis pessoal;

ii) um espaço que se constrói a partir da posição dos sujeitos em relação um ao outro e ao objeto foco da atenção conjunta e no qual a interação ocorre. Este espaço não é representado apenas por um espaço físico atual, no qual os sujeitos em atenção conjunta estão inseridos, podendo ser também um espaço que mescla dois ambientes (como veremos por meio de nossos dados que trazem a atenção conjunta entre sujeitos da realidade atual e da realidade virtual33);

iii) um tempo, presente, passado ou futuro, no qual os sujeitos e o espaço da atenção conjunta estão localizados. E especificamente nos dados que analisaremos, o tempo em que se encontram os elementos que os participantes manipulam.

Ampliando as considerações realizadas acima, em i, ii e iii, percebemos que a noção de dêixis discursiva trazida de Marcuschi (1997), como já foi exposto, está dentro do processo de atenção conjunta por meio da relação entre os sujeitos que mutuamente mantêm a atenção acerca do objeto foco, exatamente por seu papel de monitoramento da atenção. Com a figura 1 que segue, buscamos ilustrar como os quatro tipos de dêixis se enquadram na noção de atenção conjunta.

\footnotetext{
${ }^{3}$ Os conceitos de realidade atual e realidade virtual são trazidos de Lévy (2011) e adaptados por Costa Filho (2016). O primeiro destaca a interação entre sujeitos e elementos que estão em um mesmo ambiente. Já o segundo engloba a interação entre sujeitos e elementos que estão em um espaço virtual.
} 
v. 7 (2) 188-205 ago/dez 2017
Figura 1 - Representação da dêixis na atenção conjunta

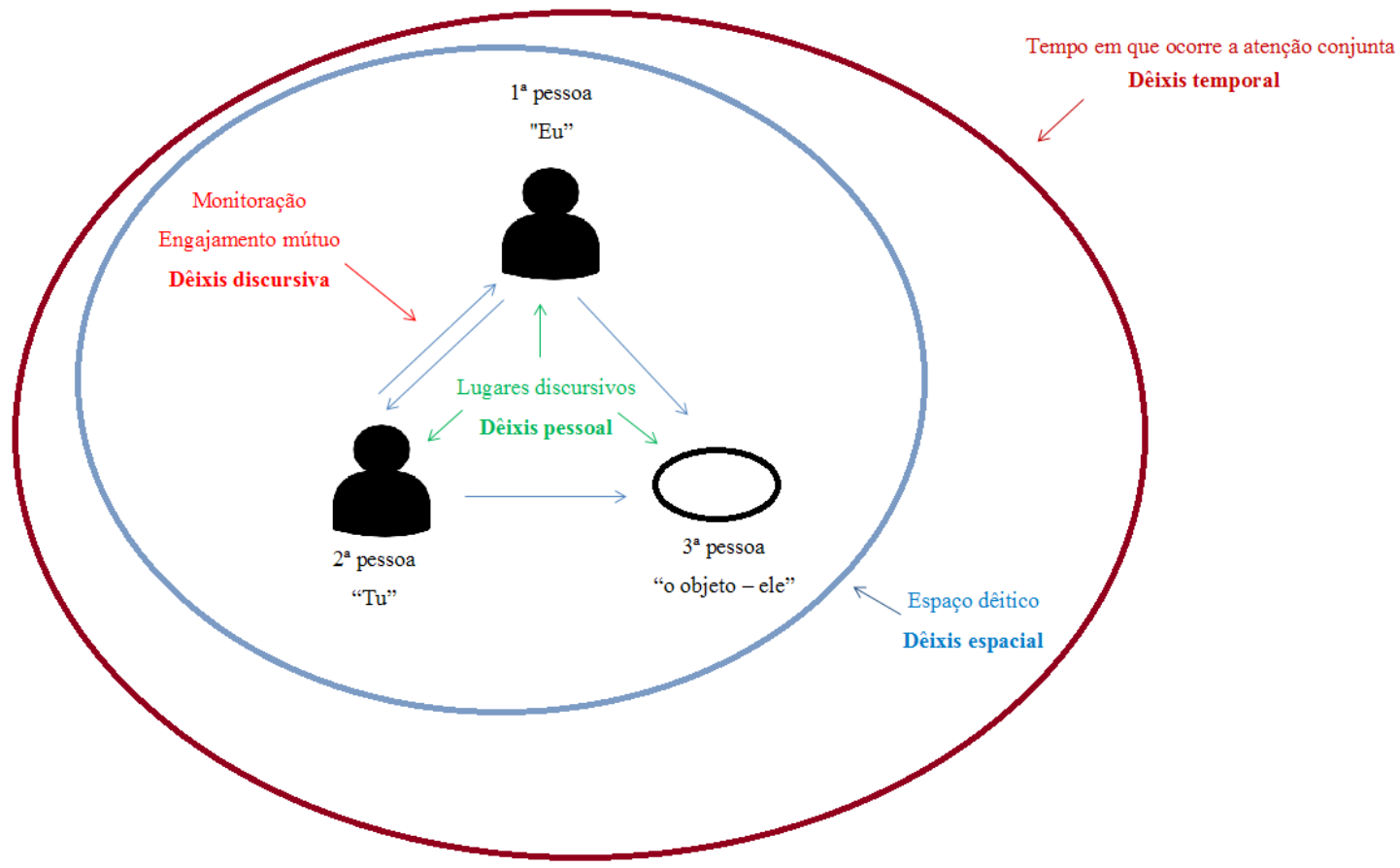

Fonte: Costa Filho (2016, p. 53)

A figura 1 evidencia no centro do formato triangular4 a dêixis pessoal. Os sujeitos na interação assumem suas posições no discurso em relação ao objeto foco. A cena de atenção conjunta ocorre, por sua vez, dentro de um espaço, o que marca a dêixis espacial. Toda a construção interativa situa-se ainda em um tempo, ou seja, está sujeita à ação da dêixis temporal responsável por estruturar o tempo da ação conjunta. Entre os sujeitos no triângulo, inseridos em um espaço e em um tempo, está a dêixis discursiva marcando a monitoração dos parceiros em relação à atenção um do outro durante o episódio de atenção conjunta.

Outro ponto que surge na discussão que envolve a atenção conjunta e a dêixis é a presença e a função do gesto de apontar no ato comunicativo, como a forma mais elementar de que lançamos mão para fazer referência a um elemento externo (TRIADÓ, 1999, p. 683), sendo, pois, o meio pelo qual se constrói a dêixis (FRICKE, 2014, p. 1803). Para Diessel (2006), tal gesto é dêitico por desempenhar o papel de coordenar o foco atencional dentro da interação, sendo por ele

${ }_{4}$ A noção de triangulação ou de formato triangular para a atenção conjunta está presente em Bruner (1975) quando este define o processo em discussão como um formato triangular em que mãe e criança têm a atenção mutuamente voltada a um terceiro objeto. 
estabelecida a atenção conjunta. Nesse mesmo sentido e emparelhando as funções do apontar e da dêixis, autores como Fricke (2014) e Cairns (1991) destacam a importância da dêixis no discurso pelo fato de que é dela a função de direcionar a atenção de um participante na troca interativa para um ponto específico no espaço e no tempo.

É preciso considerar, no entanto, que nem sempre na cena de atenção conjunta o gesto de apontar é utilizado. Principalmente em situações em que não se pode, por convenções sociais, utilizar o gesto de apontar, os interlocutores utilizam diferentes formas para manter a atenção conjunta, a exemplo de pronomes demonstrativos e outras expressões referenciais, ou ainda estratégias não verbais como o direcionamento pelo olhar, num contexto em que o movimento dos olhos substitui o movimento do dedo indicador.

De uma forma ou de outra, tanto os pronomes demonstrativos do ponto de vista verbal - quanto o apontar ou o movimento dos olhos do ponto de vista não verbal - servem para indicar a localização espacial do objeto no centro dêitico. Ou seja, é por meio de tais estratégias que a orientação espacial é alcançada e os interlocutores mantêm a atenção ao elemento referenciado no contexto (DIESSEL, 2006, p. 9).

A atenção conjunta, nesse sentido, fornece a orientação espacial necessária para que o envolvimento dos interlocutores sobre o elemento de referência se mantenha, estando este centro dêitico situado ou não no espaço visível dos interlocutores, ou ainda em um espaço que envolva um tempo diferente, como quando os participantes de uma troca interativa fazem uso do processo de atenção conjunta para narrar um fato passado.

Na seção a seguir, veremos como a referência linguística se organiza em nossos dados de episódios de atenção conjunta.

\section{Organizando a referência linguística}

Para ilustrar a organização da referência linguística nos contextos de atenção conjunta, analisamos dados coletados com vinte crianças na faixa etária de dois a cinco anos de idade, período que contempla o intervalo em que as crianças estão em processo de consolidação da linguagem por meio da construção da referência linguística.

Para a coleta de dados, que aconteceu em uma escola privada da cidade de João Pessoa, na Paraíba, onde as crianças participantes estão matriculadas em séries da Educação Infantil, utilizamos o jogo Mimi@ 
v. 7 (2) 188-205 ago/dez 2017

196

Esse jogo, desenvolvido para tablets por uma equipe multidisciplinar ${ }^{5}$, possui dez fases que progridem em termos de complexidade narrativa, nas quais o jogador precisa executar tarefas para ajudar um personagem humano - representado por uma criança virtual - a cuidar do gato Mimi a partir dos comandos fornecidos pelo narrador (ver figura 2, que apresenta a tela inicial do jogo).

Na situação proposta para a coleta de dados $^{6}$, cada criança foi convidada a jogar duas vezes com o aplicativo e os dados foram gravados por meio de duas câmeras, uma filmando o ambiente e a outra filmando a tela do tablet durante os movimentos da criança para cumprir as tarefas do jogo.

Figura 2 - Tela inicial do jogo Mimi $@$

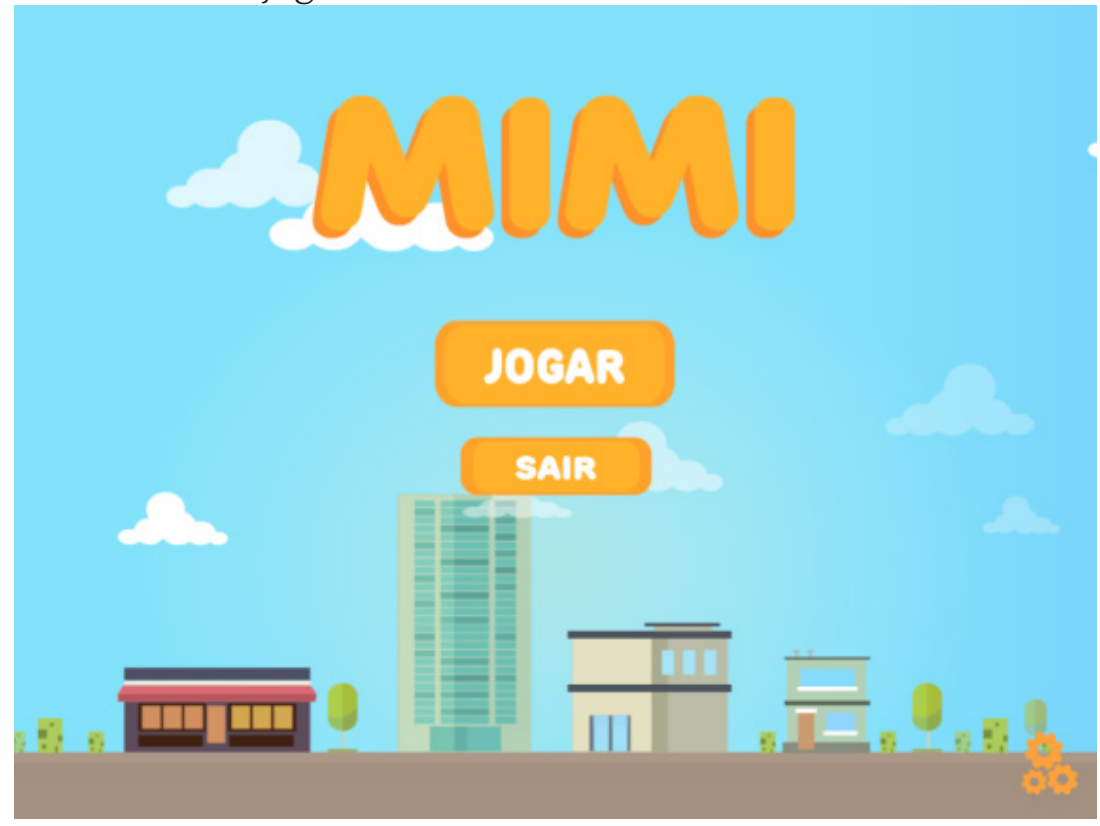

Fonte: Jogo Mimi@

Analisamos os dados do ponto de vista quantitativo para obter o número de cenas de atenção conjunta nas quais cada sujeito se engajou enquanto jogava com Mimi ${ }^{\circ}$. Ao mesmo tempo, por meio de uma

\footnotetext{
$\overline{5}$ O jogo Mimi $\subseteq$ foi desenvolvido por uma equipe multidisciplinar, da qual fazemos parte, composta por pesquisadores de Linguística, de Análise e Desenvolvimento de Sistemas e de Design Gráfico. O projeto contou com o apoio financeiro do CNPq por meio do processo 371998/2014-0, dentro do edital 84/2013 para Núcleos Nascentes em Tecnologia Assistida do Programa das Tecnologias Educacionais e Sociais. A execução do projeto que deu origem ao aplicativo aconteceu no Laboratório de Aquisição da Fala e da Escrita (LAFE), da Universidade Federal da Paraíba (UFPB), sob coordenação da Professora Doutora Marianne Carvalho Bezerra Cavalcante.

6 Como já foi mencionado anteriormente, os dados que trazemos neste artigo compuseram o corpus de nossa Tese de Doutorado intitulada "Atenção conjunta: o jogo da referência na realidade virtual".
} 
análise qualitativa, pudemos verificar a ocorrência da atenção conjunta em três formatos distintos, que também foram alvo de comparação quantitativa para compreender de que modo esses formatos se interligam. Classificamos esses formatos como atenção conjunta atual, atenção conjunta composicional e atenção conjunta virtual (COSTA FILHO, 2016).

\section{Atenção conjunta atual}

O formato identificado como atenção conjunta atual corresponde à situação em que a criança, ao jogar com o aplicativo, recorre à professora - presente durante a coleta de dados - para executar as tarefas propostas no jogo, que ocupou o lugar de objeto da atenção conjunta.

Vejamos, com o exemplo 1, de que forma a cena de atenção conjunta se constitui e como a referência linguística está presente no processo em destaque.

Exemplo 1

Criança 11 - 3 anos e 2 meses

Fase 1 - Jogada 1

Finalizado o comando do narrador, passam-se 4 segundos...

(I) Criança: olha para a professora (começando a interação de atenção conjunta atual).

(II) Professora: "Mimi é o gatinho (aponta para o gato) e Lila é a amiguinha. Você vai ter que levar ele para passear até perto da amiguinha". Pausa de 5 segundos

(III) Criança: desvia o olhar da professora para a tela e toca o gato sem realizar a tarefa.

(IV) Professora: "Pega Mimi. Cadê Mimi? Mimi é o gato. Bote ele perto da amiguinha".

(V) Criança: cumpre a tarefa.

A cena transcrita no exemplo 1 ilustra a constituição da atenção conjunta atual, em que a criança busca a professora para se engajar acerca do objeto terceiro que, na cena em destaque, é o tablet/jogo. Para analisarmos a organização referencial do exemplo 1, retomaremos os conceitos trazidos na figura 1, com a representação da dêixis na atenção conjunta, e ainda as contribuições de Marcuschi (1997) e Triadó (1999). 
v. 7 (2) 188-205 ago/dez 2017

Inicialmente, percebemos que na constituição do formato triangular da atenção conjunta em que os lugares discursivos (dêixis de pessoa) são ocupados, temos a criança ocupando o lugar da primeira pessoa que, após ouvir o comando do narrador do jogo, visivelmente não sabe como agir para realizar a tarefa proposta. A partir da não realização da tarefa do jogo, a criança dirige o olhar para seu interlocutor atual, buscando-o para a cena de atenção conjunta. A professora, então, assume o lugar de segunda pessoa na cena e passa, juntamente com a criança, a dirigir a atenção ao tablet/jogo, que ocupa o terceiro lugar discursivo dentro da cena de atenção conjunta.

Em termos de referência espacial, a cena do exemplo 1 ocorre no espaço atual, com sujeitos e objeto envolvidos no processo; todos situados em um mesmo ambiente. Ainda que o jogo esteja em evidência como objeto, não é para o que está dentro do jogo, mas sim para o próprio objeto físico que os interlocutores dirigem a atenção conjunta. O espaço é formado pela distância entre os sujeitos e o objeto na construção do triângulo da atenção conjunta. Dentro desse espaço, a dêixis se constrói não verbalmente por meio do movimento de olhar da criança (I e III) e do gesto de apontar da professora (II), e ainda verbalmente por meio de termos usados pela professora como "levar" (II) e "perto" (II e IV), que carregam a ideia de deslocamento e de distância no que se refere ao objeto da atenção conjunta.

A referência temporal, por sua vez, está focada no tempo presente, ou seja, toda a cena se desenrola no mesmo tempo da ação e, apenas por meio da explicação da professora em "Mimi é o gatinho (aponta para o gato) e Lila é a amiguinha" (II), percebemos que uma informação do passado é recuperada. A professora, no entanto, traz as informações para auxiliar a criança a cumprir a tarefa na qual ambas estão engajadas.

Em relação à organização da dêixis discursiva, responsável pela monitoração do engajamento mútuo entre os sujeitos envolvidos na cena, percebemos que tanto a criança quanto a professora lançam mão de estratégias para entrar, manter-se e realizar a ação dentro da cena de atenção conjunta. A criança restringe-se ao uso da estratégia não verbal que é o olhar direcionado à professora para buscá-la para o engajamento mútuo (I) e o olhar intercalado entre a professora e o objeto foco (III e V). Já a professora, para manter a cena de atenção conjunta e auxiliar a criança no cumprimento da tarefa, utiliza o apontar como recurso não verbal e, como estratégia verbal, lança mão de sequências como A e B: 
A) "Mimi (II, IV) $\rightarrow$ gatinho (II) $\rightarrow$ ele (II, IV) $\rightarrow$ gato (IV)".

B) "Lila (II) $\rightarrow$ amiguinha (II, IV)".

Percebemos com as sequências A e B que a professora utiliza a construção referencial (referência lexical e gramatical) na atenção conjunta e, sendo assim, a dêixis discursiva, para fazer com que a criança execute a tarefa proposta pelo narrador. A seguir, analisaremos o segundo formato de atenção conjunta identificado.

\section{Atenção conjunta composicional}

Classificado como atenção conjunta composicional, no formato em destaque, mais uma vez a criança busca a professora durante a execução da tarefa proposta pelo narrador do jogo. No entanto, após a intervenção da professora, a criança retorna a atenção ao jogo, que não é mais o objeto foco, mas sim o lugar no qual o narrador, interlocutor virtual da criança, está.

Vejamos a seguir o exemplo 2.

Exemplo 2

\section{Criança $2-4$ anos e 4 meses}

Fase 7 - Jogada 1

Finalizado o comando do narrador...

(I) Criança: em atenção conjunta virtual, tenta executar a tarefa de arrastar a bola (objeto foco da atenção conjunta virtual) até o gato Mimi, mas não consegue mover o objeto.

(II) Criança: "Não consigo não (olha para a professora)".

(III) Professora: "Vá lá que você consegue (olha para a criança e aponta para a bola)".

(IV) Criança: Volta a atenção ao jogo e com insistência consegue executar a tarefa.

A cena transcrita no exemplo 2 mostra a configuração da atenção conjunta que chamamos de composicional. Como o próprio título já antecipa, a cena em análise se constitui quando a criança transita entre a atenção conjunta atual com a professora e a atenção conjunta virtual com o interlocutor proposto no jogo, o narrador. 
v. 7 (2) 188-205 ago/dez 2017
Com o início do recorte, em (I), notamos que a criança compreende o comando do narrador e segue na tentativa de executar a ação proposta e ancorada na atenção conjunta virtual. Dentro do formato virtual, a criança e o narrador ocupam as posições de interlocutores no triângulo, que é completado pelo objeto (bola) na terceira posição. Em termos de referência pessoal, percebemos que os sujeitos que ocupam a cena de atenção conjunta interagem a partir de ambientes distintos e, em especial no que diz respeito ao narrador, que não aparece visualmente no jogo, percebemos que apenas o verbal marca a presença desse sujeito. A bola, por sua vez, é o terceiro elemento a ser manipulado pela criança 2 no momento em que, em atenção conjunta, ela utiliza o touch como forma de construir uma ponte física entre o atual e o virtual.

Embora a cena virtual esteja formada e em andamento, frente à dificuldade encontrada no movimento do objeto foco, a bola, a criança busca a professora em (II) e, com a entrada do interlocutor atual, a cena virtual dá lugar ao formato atual. Nesse sentido, criança e professora ocupam os lugares de "eu" e "tu", enquanto o jogo como um todo (e não mais um único elemento dentro dele) completa o formato triangular como o terceiro objeto, foco da atenção conjunta. O que fica evidente, porém, é que a participação da professora na cena de atenção conjunta serve de base para que a criança retorne em (IV) ao formato virtual e conclua a tarefa, momento no qual a atenção virtual é retomada, já que a verificação de que o engajamento virtual foi bem sucedido está condicionada à realização da tarefa proposta pelo interlocutor virtual.

Mais uma vez a configuração temporal da cena se passa totalmente no tempo presente. Já a configuração espacial da cena de atenção conjunta composicional é exatamente a junção entre os espaços atual e virtual. Sob o ponto de vista atual, a atenção conjunta se constitui espacialmente entre as distâncias da criança em relação à professora e de ambos os interlocutores atuais em relação ao jogo/tablet. Na configuração virtual, o espaço já se constitui por meio da mescla entre atual e virtual, ou seja, esta noção espacial é constituída pela distância entre a criança e o objeto foco que está dentro da tela do tablet e ainda pela distância entre o objeto que a criança precisa manipular e o lugar para onde o objeto precisa ser levado (na cena em questão, para junto do gato Mimi).

A organização discursiva, assim como a espacial, é marcada pelo percurso que a criança faz entre as configurações atual e virtual na atenção conjunta do tipo composicional. Do ponto de vista da criança, 
na atenção virtual, o engajamento é sustentado apenas pelo olhar que ela dirige à tela do jogo (tanto em I quanto em IV), já que esta criança não se dirige verbalmente ao narrador. Também na cena atual, a criança utiliza o olhar para buscar a atenção da professora (II). A professora, no entanto, quando entra em atenção conjunta com a criança, além de utilizar o olhar na confirmação de que vai se engajar na interação, faz uso do apontar em direção ao objeto foco (III), quando instrui a criança sobre o que deve ser feito para o cumprimento da ação. O olhar da criança em (II) e o apontar da professora em (III) são gestos equivalentes que sustentam, de modo não verbal, o engajamento mútuo dentro da dêixis discursiva.

Por fim, um ponto que também merece destaque é a produção verbal da professora em (III). Percebemos que, por meio do referencial "lá", a professora reafirma a sua posição dentro da cena de atenção conjunta e o termo referencial marca a sua distância, como sujeito situado na realidade atual, entre o objeto que está na realidade virtual, um espaço distante porque a professora se posiciona como um sujeito que não entrará na atenção conjunta virtual, mas sim, ajudará a criança a fazê-lo.

Nessa realidade virtual, inclusive, está o terceiro formato de atenção conjunta que verificamos, como veremos a seguir.

\section{Atenção conjunta virtual}

O formato de atenção conjunta virtual evidencia uma cena em que a criança interage diretamente com o interlocutor virtual durante a realização da tarefa. Uma particularidade observada por Costa Filho (2016) sobre essa configuração de atenção conjunta é o fato de que, frente às tarefas do jogo Mimi, apenas podem ser vistas como cenas de atenção conjunta virtual aquelas situações em que a criança realize a tarefa proposta pelo jogo. Em casos em que a criança não realize a tarefa, mas demonstre certo engajamento com o narrador situado no ambiente virtual, a cena de atenção conjunta se estabelece parcialmente. Esse, no entanto, não é o foco da presente discussão. Passemos, portanto, ao exemplo 3 que ilustra uma cena de atenção conjunta virtual. 
v. 7 (2)

188-205

ago/dez 2017

Exemplo 3

\section{Criança 3 - 4 anos e 1 mês}

\section{Fase 3 - Jogada 2}

Após iniciado a fase com o comando do narrador, a criança está em atenção conjunta virtual, atenta aos comandos que partem da realidade virtual.

(I) Narrador: "Você consegue ver onde tá o leite de Mimi?".

(II) Criança: "Aqui (toca a tela em cima do leite de Mimi, enquanto se mantém atenta ao jogo e, em seguida, começa a arrastar o objeto foco para o cumprimento da tarefa)".

(III) Narrador: "Então vamos lá! Traga o leite para Lila".

Em comparação aos exemplos 1 e 2, a primeira evidência que reforça a consolidação da atenção conjunta virtual é a ausência da professora na cena transcrita. Somente o narrador do jogo, a partir do ambiente virtual, é tomado pela criança como interlocutor, o que dá à cena o formato virtual.

No que se refere à noção de referência pessoal, vemos que a criança assume a primeira posição e, a partir de seu lugar na realidade atual, interage com um "tu" que está dentro da realidade virtual acerca de um objeto dentro da mesma realidade trazido à cena por este interlocutor.

A organização espacial da cena, por sua vez, é marcada na fala do narrador (I) quando ele questiona a criança sobre o local onde se encontra o objeto foco da atenção conjunta virtual, propondo, por meio de sua pergunta à criança, que o olhar do jogador se volte para tal objeto. Em resposta ao narrador, a criança em (II) reconhece o objeto foco não verbalmente com o gesto de touch e verbalmente com "aqui". Em termos não verbais, o touch mais uma vez substitui o apontar que convencionalmente utilizamos nas interações atuais. Associado ao advérbio "aqui", este gesto mostra a construção da referência espacial pela criança que se coloca próxima ao objeto, embora ele esteja em um ambiente diferente do que ela se localiza. Isso é possível por meio do engajamento de atenção virtual que permite que a criança transite entre as duas realidades para interagir com seu interlocutor virtual e cumprir a tarefa proposta pelo jogo. Nesse ponto, o objeto foco está perto da criança e ela reconhece como sua tarefa, que começa a cumprir ainda em (II), traçar o deslocamento do objeto foco de junto de si para o ponto em que está a personagem Lila, à espera do leite. 
Por fim, a organização temporal da cena se dá toda no presente, sem que haja referências a dados trazidos anteriormente no jogo. Não podemos, no entanto, generalizar que a atenção conjunta virtual se desenvolve no tempo presente, já que neste tipo de interação - assim como em qualquer outro formato interativo - os sujeitos envolvidos podem organizar o discurso por meio de variados recursos que remetem a informações do passado, quando estas são importantes para a consolidação do engajamento conjunto.

Após a exposição dos exemplos 1, 2 e 3, ilustrando os tipos de atenção conjunta identificados na pesquisa e a forma como as noções de referência se organizam, apresentaremos a seguir algumas considerações finais sobre a pesquisa.

\section{Considerações finais}

Ao final deste artigo, percebemos que a atenção conjunta não é um funcionamento que se estabiliza de forma simples na rotina da criança, mas sim um processo complexo que é construído por meio de ações que ancoram o envolvimento conjunto em torno de um objeto. Talvez seja exatamente por sua complexidade que a atenção conjunta varia conforme a sofisticação das estratégias envolvidas para seu estabelecimento e manutenção, e que, ao contrário de algumas abordagens de pesquisa que consideram a atenção conjunta apenas na rotina de crianças em fase de aquisição da linguagem, este processo permanece ao longo do tempo e faz parte das interações sociais de crianças maiores, como é o caso do grupo de sujeitos que participaram da pesquisa cujo recorte foi apresentado.

Observando os três exemplos trazidos, verificamos que independentemente dos formatos (atual, composicional ou virtual), a cena de atenção conjunta tem uma configuração que está alicerçada na organização referencial. Isso porque a atenção conjunta é "o palco sobre o qual a referência linguística atua, tendo o contexto como ponto de interseção que torna interdependentes os processos de atenção conjunta e de referência linguística" (COSTA FILHO, 2016, p. 55).

Para a criança em processo de consolidação da referência linguística, portanto, a cena de atenção conjunta se apresenta como um lócus privilegiado que permite que as noções referenciais sejam ritualizadas. Frente ao jogo Mimi ${ }^{\complement}$, especificamente, a noção de pessoa é tomada pela criança quando ela busca o interlocutor atual (exemplos 1 
v. $7(2)$ 188-205 ago/dez 2017

e 2) e quando ela "aceita" a proposta de interação feita pelo interlocutor virtual (exemplo 3).

A noção de espaço, por sua vez, é marcada para a criança que precisa se localizar dentro da cena, compreendendo onde estão seus interlocutores (atual ou virtual), o objeto foco da cena e ainda a distância ou o percurso que este objeto precisa percorrer dentro do jogo para que a tarefa seja cumprida. Também com fins de auxiliar o cumprimento da tarefa, vimos que no exemplo 1 a professora, interlocutor atual da criança, utilizou dados do passado para que a ação fosse consolidada pela criança dentro do presente. Esse dado ilustra pelo menos uma das contribuições da referência temporal para a manutenção da atenção conjunta. Pensando, por fim, na dêixis discursiva, vimos que este processo é primordial para que os sujeitos estabeleçam, regulem e mantenham a atenção conjunta em volta de um determinado objeto.

\section{Referências}

BRUNER, J. Childs Talk: Learning to use language. New York: Norton, 1983.

From communication to language: a psychological perspective. Cognition, v. 3, n. 3, p. 255-287, 1975.

CAIRNS, B. Spatial deixis: the use of spatial co-ordinates in spoken language. Working Papers, Sweden, n. 38, p. 19-28, 1991.

COSTA FILHO, J. M. S. da. Atenção conjunta: o jogo da referência na realidade virtual. 2016. 215 p. Tese (Doutorado em Linguística) - Universidade Federal da Paraíba, João Pessoa, 2016.

Atenção conjunta e desenho animado: da interação à referência linguística. DLCV (UFPB), v. 10, n. 1 e 2, p. 105-120, jan/dez. 2013.

"Olá, Pocoyo!": a constituição da atenção conjunta infantil com o desenho animado. 2011. 139 p. Dissertação (Mestrado em Linguística) Universidade Federal da Paraíba, João Pessoa, 2011.

DIESSEL, H. Demonstratives, joint attention, and the emergence of grammar. Cognitive Linguistics, v. 17, p. 463-489, 2006.

FRICKE, E. Deixis, gesture, and embodiment from a linguistic point of view. In: MÜLLER, C. et. al. (orgs). Body - Language - Communication: An International Handbook on Multimodality in Human Interaction. Berlin, Boston: De Gruyter Mouton, 2014. p. 1802-1823.

KOCH, I. V. O texto e a construção dos sentidos. 2. ed. São Paulo: Contexto, 1998. 
LÉVY, P. O que é o virtual? Tradução de Paulo Neves. 2. ed. São Paulo: Editora 34.

MARCUSCHI, L. A. A dêixis discursiva como estratégia de monitoração cognitiva. In: KOCH, I. V.; BARROS, K. S. M. Tópicos em Linguística de texto e análise de conversação. Natal: EDUFRN, 1997.

SILVA, F. E. V. da; LIRA, P. S. de; CAVALCANTI, S. B. Aspectos do processo de referenciação na aquisição da linguagem: do linguístico ao extralinguístico. Revista Ao Pé da Letra, v. 3, n. 2, p. 47-58, 2001.

TRIADÓ, C. Deixis acquisition in deaf and hearing children. In: Psycholinguistics on the threshold of the year 2000: proceedings of the $5^{\text {th }}$ International Congress of the International Society of Applied Psycholinguistics. Porto: Faculdade de Letras da Universidade do Porto, 1999. p. 683-686.

TOMASELLO, M. Origens Culturais da Aquisição do Conhecimento Humano. Tradução de Cláudia Berliner. Martins Fontes: São Paulo, 2003.

Recebido em: 15 de fev. de 2017.

Aceito em: 3 de jul. de 2017. 